\title{
Studying the Impact of Leadership Style on Organizational Culture in New Agencies Under the Ministry of Culture and Islamic Guidance
}

Keywords: Organizational culture, leadership style, individual behavior, Islamic guidance.

JEL Classification: D83, O32.

Research type: Research paper.

\footnotetext{
${ }^{1}$ Ph.D., Student in Communication Sciences, Tabriz Branch, Islamic Azad Unicersity, Tabriz, Iran,hassan.amidi@yahoo.com;

${ }^{2}$ Corresponding author, Assistant Professor, Department of Communication, Tabriz Branch, Islamic Azad Unicersity, Tabriz, Iran, $m$ samadi426@yahoo.com;

${ }^{3}$ Assistant Professor, Department of Psychology, Urmia Branch, Islamic Azad Unicersity, Tabriz,Iran, huseyn.hunarvar@gmail.com;

${ }^{4}$ Assistant Professor, Department of Communication, Tabriz Branch, Islamic Azad Unicersity, Tabriz,Iran, goopgoopi@gmail.com;
} 


\section{Introduction}

Efficient human resources are considered the wealthiest and most valuable property of any organization. Despite having multiple sources, many of the organizations are not able to use these facilities due to a lack of qualified and specialized human resources. While, some organizations, despite the lack of sources, have achieved growth and excellence due to having experienced and appropriate human resources and are progressing with long and firm steps. Therefore, rapid economic, political, and social changes made managers face new issues regarding the type of treatment with the employees in organizations (Ramanaidu, 2011). Organizational behavior seeks to find scientific and practical methods to increase the efficiency and effectiveness of employees in the organization- the knowledge of organizational behavior roots in the organization and management theories. If the human resource is treated and supported correctly, it can be positive and in line with the organization's goals. Otherwise, it takes steps against the goals of the organization (Castiglione, 2016).

Understanding the behavior of human resources is of particular importance for management. Of course, it is not just to hire people in the organization but to connect them with the organization and create mutual solidarity between the individual and the organization. Many people keep working in the organization for years since they have no other option. In this case, they help the organization resolve the problems, but if they have the opportunity, they put a heavy burden on the organization (Lim and Croartie, 2013).

Therefore, to increase employee morale, job satisfaction, and organizational commitment, it is necessary to focus on meeting their needs in the workplace. Only managers can meet the high-level needs of the employees and create the right psychological atmosphere within the organization. It will be possible through organizational culture (Aghajani et al., 2012).

Organizational culture, leadership style, and news management, and ultimately effective communication with the people are essential categories since they play a vital role in the growth and excellence of a media organization (Santoso et al., 2020; Dulewicz and Higgs, 2005). In this regard, it is possible to consider the role of organizational culture and its significant impact on individual behavior and organizational behavior (Reidhead, 2020; Setiawan, 2020). The organizational culture, as a fundamental factor, has a significant impact on other critical organizational aspects, including the structure and design of the organization, the internal and external environment of the organization, human resources, and most importantly, leadership style and the strategy to achieve the organizational goals (Aghajani et al., 2012). If the organization members do not have any information about their organizational culture, they will not be able to understand the nature of the organization and its goals. On the other hand, communicating with the employees to create a positive attitude about the organization can be helpful (Hosseini, 2010). Proper communication with employees, the appropriate leadership style, and the 
desired model of organizational culture are interconnected so that their weaknesses or incompatibility can hinder the growth and excellence of the organization (Purba et al., 2021; Atikah and Qomariah, 2020; Erniwati, 2020).

News agencies and media organizations are among the essential means to countercultural invasion. Due to the change in the domination system from brutal war to soft war and change of the confrontation field from military to the economic, political and cultural field, the primary way to affect the audience is to attract their attention and trust the media. Also, by considering the significant impact of organizational culture, media organizations, and their performance, especially in attracting loyal audiences, doing this research can help us identify the potential problems and barriers of news agencies. Ignoring the most important factors affecting the performance of media organizations, in the long run, will lead to the audience's low attention and trust in local media.

Consequently, we will see a decrease in the number of local media audiences and an increase in attention to foreign media, especially satellite networks (Fein et al., 2010). Of course, giving accurate information is available through communication with the audience. In other words, continuous communication can inform the organization from the news and cultural needs of the audience so that based on the achieved information, an organization can take action to meet the needs. However, it depends on the media's prevailing organizational culture and leadership style (Eyal and Kark, 2004). To be clear, if the media's leadership style and organizational culture are in line with the needs and interests of the audience, communication and being aware of the audience's needs will be possible. Otherwise, the organization will distance itself from its essential purpose and philosophy. Since the performance of any organization, including media organizations, is directly influenced by the leadership style of senior managers and the prevailing organizational culture (Rozi et al., 2020; Wanasida et al., 2021) and also considering that one of the most important criteria for a media success is attracting the attention of the audience, this study aims to evaluate the impact of leadership style on organizational culture in news agencies under the Ministry of Culture and Islamic Guidance.

\section{Literature Review}

The term "organizational culture" refers to the organization's fundamental values, core assumptions, expectations, shared memories, and definitions. It refers to the dominant ideology in people's minds. It expresses employee similarity, preparing unwritten rules, mental instructions in the organization, and increasing the social system's stability (Daneshfard and Shahabinia, 2011). Organizational culture is a set of organizational value systems and shared beliefs of the organization members. It is said that the organization's culture is formed by the structure and goals and tasks of the organization, atmosphere, values, and personal beliefs, considering that the mentioned factors affect the organization's performance (Delavar, 2011). Organizational culture refers to a system of shared inferences among the members of an organization, and it 
separates the organizations from each other. Chris Argyris calls organizational culture "a living system" and defines it based on people's behavior in action, the way of thinking and feeling, and the way of treating each other.

According to Edgar Schein, organizational culture is a model based on the assumptions that group members learn to solve problems in adapting to the external environment and its internal development, and works so well that it is recognized as a valid method and thought to the new members to use them in solving the organizational problems. James Percy believes that organization members have shared values, beliefs, specific language, codes, and other thinking and behavioral patterns, and in short, he defines organizational culture as "a model of the common goals of organization members" (Ramanido, 2011).

Talcott Parsons provided a comprehensive analytical model for analyzing the types of group activities. His model is known as "AGIL". It indicates that social systems must have four essential functions to survive, and depending on the organization's social environment each organization emphasizes the following functions, adaptation, goal achievement, cohesion, integration, and latency (Tusi, 2013). Mackenzie's company has a significant role in shaping the concept of "organizational culture" in management. During the 1980s, the company published at least five best-selling books on organizational culture in collaboration with the leading researchers from famous American universities, including Ward and Stanford. One of these writings introduces seven important factors as influential organizational culture factors, each of which begins with the letter "S" (Gholami et al., 2013).

According to these authors, the organizational structure and standard systems in the organization are considered three complex factors, and the manager's style, staff skills, and finally, the dominant goals are also considered soft factors in organizational culture. These factors can ensure the organization's effectiveness by matching and correlating with each other (Fisher, 1979). Kurt Levine focused on management style in his studies. He concluded that a human-centered atmosphere would lead to highlevel performance and satisfaction. Factors that make up the organizational culture are leadership processes, motivation, communication, decision making, goal setting, interaction, and control. Levine's model mainly focuses on behavioral factors (Gholipour, 2011).

Considering the importance of identifying the culture and functions and its effect on the organization employees, various models have been designed and presented for being used in the researches related to organizational culture. The main topics in the models are evolution and stability, attention to the capabilities and empowerment, adaptation versus challenge, convergence versus divergence, reaction to the ambiguity and uncertainty, etc. One of the models is Denison's model (Karami, 2015). Professor Daniel Dennison (2000) researched organizational culture and organizational effectiveness. In his model, he defined the cultural characteristics as follows (Kaskin, 2014), involvement in work, adaptation, and mission. Quinn and Gareth also divided 
organizational culture into four categories, rational culture, ideological culture, hierarchical culture, and participatory culture. They also introduced nine significant organizational variables which have a specific place in these cultures. According to them, the culture of any organization can be placed in a specific cultural group.

Rational culture: In rational culture, the organizations' goals are pretty straightforward, and all the employees try to achieve the goals. Here, the employee performance is measured based on their work efficiency, the manager has authority, and what is essential is rational decision and competence in leadership style.

Ideological culture: In this culture, the organizations aim to achieve broad goals. The employer or a superior and spiritual person has the authority. The decision-making is often judgmental, and the source power is the values governing the organization. In most situations, leadership is conducted individually.

Participatory culture: The aim of these organizations is often the survival of the group. The measurement of members' performance is based on group cohesion, and the reference of the power is the membership of each member in the group. Decisionmaking is participatory, and commitment to the group values is the key to success, and finally, intimacy and correlation are considered the organizational motivations.

Hierarchical culture: In this culture, the execution of commands and instructions is the organization's goal, and the measurement of the performance is based on stability and control. The decision-making process is based on technical knowledge, and accordingly, the source of power is distributed hierarchically and considering the level of knowledge (Garvey et al., 2002).

\section{Research Methodology}

Sarraf and Rokhchekar (2018) conducted a study entitled "explaining the relationship between transformational leadership style, organizational culture, and performance." The required data were collected through library studies. The result showed that leadership style positively affects organizational culture and performance, and there are clear and significant relationships between the components.

Jafari Harandi and Najafi (2017) conducted a study entitled "The Impact of Leadership Style on Human Resource Performance Mediated by Organizational Silence." The research is correlational and was conducted using Structural Equation Modeling (SEM). The statistical population consisted of 430 employees of Sepah Banks in Sari city. The sample size was estimated to be 203 employees selected using multi-stage cluster, random sampling and Cochran's formula. Data were analyzed using SPSS and Lisrel software. The results showed that transformational and exchange leadership styles have a positive and significant relationship with organizational performance, while organizational silence has a negative relationship with organizational performance. Transformational leadership increases the employee's performance by 
mediating organizational silence, and exchange leadership reduce performance through organizational silence. Transformational leadership has a negative relationship with organizational silence, while exchange leadership has a positive relationship with organizational silence.

Samadi Miarkalaei et al. (2016) conducted a study entitled "Explaining the role of transformational leadership style in organizational culture." The statistical population of this study includes 113 employees of the Education Department in Mazandaran province, from whom 102 people were selected as the research sample. Data were collected using a questionnaire and analyzed by SPSS and LISREL software. The findings showed a relatively strong positive and significant relationship between transformational leadership and organizational culture. Also, all aspects of transformational leadership styles are positively and meaningfully related to organizational culture.

Aghajani et al. (2012) conducted a study entitled "Studying the effect of leadership style on organizational culture. The statistical population included 242 employees of the Pars Industrial Company of Kaveh. The analysis of the collected data using a questionnaire was performed by the Structural Equation Modeling (SEM) with the help of SMART PLS 2.0 software in two parts, model measurement part and structural part. In the first part, the technical characteristics of the questionnaire were evaluated based on the reliability, convergent validity, and divergent validity specific to PLS, and the necessary corrections were made. In the second part, the structural coefficients of the model were used to test the research hypotheses. The results confirmed the positive and significant effect of leadership style on organizational culture in the research community.

Ozcan and Ozturk (2020) studied the Impact of Organizational Culture and Leadership Styles on Employee Performance in Turkey. This study was quantitative research, and the data were obtained from the employees of a private bank and analyzed using SPSS 24 software. The results showed that organizational culture plays a vital role in leadership style and employee performance. The leadership style also has a significant impact on the employee's performance.

Khan et al. (2020) studied Interplay of Leadership Styles, Innovative Work Behavior, Organizational Culture and Organizational Citizenship Behavior among higher education institutions in Pakistan. In this study, the survey method was used, and 160 people were selected as the study sample. The study results showed that leadership styles have a positive effect on innovation behaviors of employees, which highlights the mediating role of organizational culture.

Nguyen (2010) conducted a study entitled "The effect of leadership style and organizational culture on knowledge management in small and medium-sized organizations." In this study, a multi-factor leadership questionnaire was used to measure the leadership style. It measures the transformational and exchangeable 
leadership style. To measure the organizational culture, the "Denison model" developed by Phi and Denison (2003) was used, and to measure the knowledge management, a 17-item questionnaire presented by Beckra-Fenands and Saberwall (2001) was used. The study results showed that transformational and exchange leadership style has a positive correlation with knowledge management. Effective leadership style depends on the type of organizational culture. Evidence also shows that an appropriate leadership style (transformational or exchange) has the largest share in organizational culture, and leaders can influence knowledge management practices directly or indirectly through organizational culture. Of course, it should be noted that understanding the transformational leadership and organizational culture may be subject to other underlying conditions such as national culture, organizational history, and performance.

Castiglione (2016), in a study entitled "Helping staff creativity in the library environment: an important concern for library managers," found that the creativity of the individual flourishes if the culture of the organization welcomes it. Ramanido (2011) conducted a study to discover the relationship between Transformational Leadership, Organizational Culture, Emotional Commitment, and Employee Performance among Educational Institutions in Malaysia. He found that organizational culture is positively associated with transformational leadership and employee performance. Also, transformational leadership mediates the relationship between organizational culture and employee performance.

In a study entitled "Transformational Leadership, Individual Creativity and Organizational Innovation," Gumusluoglu and Ilsey (2009) found a positive and significant relationship between transformational leadership and employee creativity, and transformational leadership affects employee creativity through psychological empowerment. Findings also showed that transformational leadership has a positive relationship with organizational innovation.

Keskin (2014), in a study entitled "Leadership Tendency and Innovation Capabilities in Small and Medium Businesses," found that organizational culture can be used to promote and support creativity and innovation. Lim and Croartie (2013), in a study entitled "The relationship between transformational and pragmatic leadership style with organizational culture," found a significant relationship between transformational leadership and organizational culture. Also, organizational culture has a significant effect on organizational effectiveness.

Based on the theoretical and empirical foundations, the analytical model of research on the relationship between leadership style and its dimensions (organizational behavior, individual behavior, and internal intention) and organizational culture can be presented as follows (Figure 1): 
Figure 1. Analytical Model of the Research

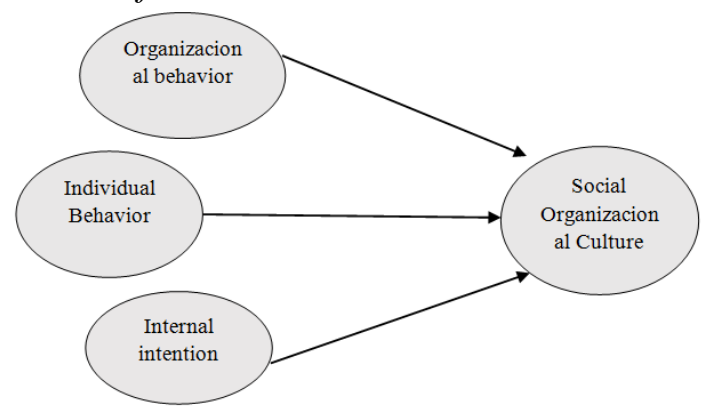

Source: Own creation.

Based on the relationships presented in the analytical model, the research hypotheses are formulated as follows:

- There is a significant relationship between leadership style and organizational culture among the staff of news agencies under the Ministry of Culture and Islamic Guidance.

- There is a significant relationship between leadership style and organizational culture among the staff of news agencies under the Ministry of Culture and Islamic Guidance.

- There is a significant relationship between the individual behavior of leadership style and organizational culture among the staff of news agencies under the Ministry of Culture and Islamic Guidance.

- There is a significant relationship between the internal intention of leadership style and organizational culture among the staff of news agencies under the Ministry of Culture and Islamic Guidance.

\section{Methodology}

Based on its purpose, the present study is an applied and a survey study. It is also extensive in terms of depth and cross-sectional according to the time criterion. The data collection tool was a questionnaire. The study's statistical population includes all employees of news agencies under the Ministry of Culture and Islamic Guidance, who were 500 people. The estimated sample included 217 people selected using a simple random sampling method and Cochran's formula. The collected data were analyzed using SPSS software:

$$
n=\frac{N t^{2} p q}{\varepsilon^{2}(N-1)+t^{2} p q}=\frac{500 \times 1.96 \times 0.5 \times 0.5}{(0.05)^{2} \times(500-1)+(1.96 \times 0.5 \times 0.5)}=217
$$

Organizational culture: Conceptually, organizational culture includes the dominant beliefs, feelings, and norms people believe in and follow (Abzari, 2006). Robbins defines organizational culture as a system of shared meanings maintained by the 
organization members and leads to the differentiation of the organizations (Ansari, 2011). Organizational culture has been measured in different dimensions; strategybased culture, human-centered culture, environment-based culture, law-based culture, and value-based culture. It was measured using 56 items on a 5-point Likert scale.

Leadership style: Conceptually, according to Tannenbaum, leadership means using the communication process in a specific situation to influence people and lead them towards particular goals. According to Daughtrey and Ricks, leadership is the ability to influence people and set goals. It makes sense of loyalty and cooperation concerning them. Stevenson and his colleagues define leadership as the ability to influence others effectively using their knowledge, skills, and insights (Erich et al., 2010).

Leadership style is also a behavioral model that expresses the behavioral traits and characteristics of leaders. In today's world, the manager's role as a leader has become so important that there is a constant effort to find people with leadership ability in all fields. If this role is not performed, as if nothing is done. The leader must assess the strength and desire of the individual or group, and based on his power; he must choose one of the leadership styles in dealing with them. Leadership style also reflects leaders' mindset, worldview, and personality (Pinder and Harlos, 2015). Operationally, leadership style has been measured in three dimensions; organizational behavior, individual behavior, and internal intention using 24 items through a 5-point Likert scale.

Content validity was used to assess the validity of the criteria, and Cronbach's alpha coefficient was used to assess its reliability. The estimated Cronbach's alpha value of the organizational culture is 0.838 , and the organizational behavior is 0.825 , the individual behavior is 0.757 , and the internal intention equals 0.856 , all of which are above 0.7 . It shows that they are in the desired and acceptable range

\section{Findings}

According to the results of Table 1, 14.4\% (27 people) respondents are female, and 87.6\% (191 people) are male. Also, according to the findings of the table, 6.9\% (15 people) of respondents had a diploma, 3.2\% (7 people) had a postgraduate degree, $66.1 \%$ (144 people) had a bachelor's degree, and 23.9\% (52 people) had a master's degree or higher.

Table 1. Descriptive statistics of research distance indices

\begin{tabular}{|l|l|l|l|l|l|}
\hline Percent & Frequencies & Gender & Percent & Frequencies & Education \\
\hline 12.4 & 27 & Female & 6.9 & 15 & Diploma \\
\hline & & & 3.2 & 7 & Associate degree \\
\hline 87.6 & 191 & Male & 66.1 & 144 & Bachelor \\
\hline & & & 23.9 & 52 & M.A \\
\hline 100 & 218 & Total & 100 & 218 & Total \\
\hline
\end{tabular}

Source: Own creation. 
According to the results presented in Table 2, the range of changes in organizational culture is from 2 to 4.84 , and its average is 4.12 (equal to 74.6 on a scale of $0-100$ ) with a standard deviation of 0.56 , which shows that the average score of organizational culture is above the average on the spectrum. From the respondents' view, the organizational culture is in good condition in their organization. Also, the range of changes in the leadership style index is from 2.63 to 4.83 . The average of the leadership style index is 4.1 (equal to 66.8 on a scale of $0-100$ ), and its standard deviation is 0.42 , which indicates that the average score of leadership style is higher than the middle of the spectrum and respondents are relatively satisfied from the leadership style of their organization.

Table 2. Descriptive statistics related to research distance indices

\begin{tabular}{|l|l|l|l|l|l|}
\hline Index & Min. & \multicolumn{2}{|l|}{ Mean } & Max. & $\begin{array}{l}\text { Standard } \\
\text { deviation }\end{array}$ \\
\cline { 3 - 4 } & & Statistics & Standard Error & & \\
\hline $\begin{array}{l}\text { Organizational } \\
\text { Culture }\end{array}$ & 2 & 4.12 & 0.038 & 4.84 & 0.56 \\
\hline leadership style & 2.63 & 4.1 & 0.028 & 4.83 & 0.42 \\
\hline $\begin{array}{l}\text { organizational } \\
\text { behavior }\end{array}$ & 2.62 & 4.17 & 0.033 & 5 & 0.49 \\
\hline individual behavior & 2.38 & 3.18 & 0.033 & 4.88 & 0.5 \\
\hline inner intention & 2.38 & 4.24 & 0.035 & 5 & 0.52 \\
\hline
\end{tabular}

Source: Own creation.

According to Table 2, the range of changes in the index of leadership style is from 2.62 to 5 . The average of this index is 4.17 (equivalent to 65.1 on a scale of $0-100$ ), and the standard deviation is 0.49 , which indicates that the average score of organizational behavior is higher than the middle of the spectrum. Also, the range of changes in the individual behavior of leadership style is from 2.38 to 4.88 , and the average of this index is 3.88 (equivalent to 52.9 on a scale of -100), and the standard deviation is 0.5 , which indicates that the average score of the individual behavior is almost in the middle of the spectrum. The range of changes in the internal intention as one of the leadership style dimensions is from 2.38 to 5. Moreover, the average of this index is equal to 4.24 (equivalent to 70.9 on a scale of $0-100$ ), and the standard deviation is 0.52 , which indicates that the average score of the internal intention is higher than the middle of the spectrum.

Table 3. Results of the correlation test of organizational culture and leadership style

\begin{tabular}{|l|l|l|}
\hline \multirow{2}{*}{ Independent Variables } & Organizational Culture \\
\cline { 2 - 3 } & Correlation coefficient & Sig. \\
\hline Leadership style & 0.672 & 0.000 \\
\hline $\begin{array}{l}\text { Organizational } \\
\text { behavior }\end{array}$ & 0.591 & 0.000 \\
\hline Individual behavior & 0.514 & 0.000 \\
\hline Internal intention & 0.578 & 0.000 \\
\hline
\end{tabular}

Source: Own creation. 
To assess the impact of independent variables on organizational culture, the regression model of organizational culture is briefly presented and discussed. To perform the regression test, its assumptions must first be evaluated. Based on the results, the general assumptions of regression analysis are the normal distribution of dependent and independent variables as well as a normal distribution of regression residuals; the linear relationship between independent and dependent variables, non-alignment between independent variables, uniformity of variances; independence of errors are evaluated using appropriate statistics or graphs and all of them have confirmed the results.

The regression analysis test of organizational culture (Table 4) shows that all independent variables (organizational behavior, individual behavior, and internal intention) entered into the regression model significantly affect organizational culture. These variables explain $45 \%$ of the changes in the dependent variable. Based on the $F$ test, the simultaneous effect of three independent variables on the dependent variable is statistically significant $(\mathrm{F}=0.000$ and $\mathrm{F}=60.71)$.

Accuracy in the value of non-Standard regression coefficient (B) related to organizational behavior indicates that a unit increase in the score of organizational behavior leads to an increase in the dependent variable of research (organizational culture). This was a statistically significant effect in the regression model due to the significance level of the t-test. Based on the non-standard coefficient of internal intention, this variable has also had a significant effect on the dependent variable of the research. Thus, an increase in the score of internal intention leads to an increase in the dependent variable.

Table 4. Results of multivariate linear regression model for non-home food consumption

\begin{tabular}{|l|l|l|l|l|l|}
\hline \multirow{2}{*}{ Independent variables } & \multicolumn{2}{|l|}{ Non standard coefficients } & \multirow{2}{*}{ Beta } & $\mathrm{t}$ & \multirow{2}{*}{ Sig. } \\
\cline { 2 - 3 } & $\mathrm{B}$ & Standard error & & & \\
\hline Constant & 0.428 & 0.276 & - & 2.48 & 0.014 \\
\hline Organizational behavior & 0.405 & 0.069 & 0.359 & 5.83 & 0.000 \\
\hline Internal intention & 0.277 & 0.074 & 0.259 & 3.72 & 0.000 \\
\hline Individual behavior & 0.215 & 0.73 & 0.19 & 2.93 & 0.004 \\
\hline R2=0/46 Adj. R2=0/45 F= 60/711 & Sig. F= 0/000 & \\
\hline
\end{tabular}

Source: Own creation.

Also, the accuracy in the value of non-Standard regression coefficient (B) related to individual behavior indicates that a unit increase in the score of individual behavior leads to an increase in the organizational culture variable by 0.215 . Due to the significance level of the t-test, this effect was statistically significant in the regression model. Based on the standard coefficients related to independent variables (organizational behavior, individual behavior, and internal intention) of the model, the organizational behavior $(B e t a=0.359)$ had a higher relative impact on organizational 
culture than other independent variables. Then, the internal intention (Beta=0.259) and individual behavior (Beta $=0.19$ ) were practical, respectively.

\section{Discussion}

Experts evaluate the success or failure of media organizations in informing their audiences, and the organization communicates with its audience. However, various organizations and institutions witness the instability and disruption in the patterns of analysis of constantly changing trends and currents governing the organizations. Heterogeneous and conflicting short-term decisions about the employees reflect this confusion. The concept of "communication with the audience" is a multidimensional concept that in order to evaluate it successfully, other important variables, including the pattern of organizational culture and leadership style, must be considered since it is the organizational culture and leadership style that determines the orientation of organizational goals and their tools. Over the past few decades, organizational culture, leadership style, and communication with audiences in media organizations have become essential topics in scientific research. Accordingly, the present study evaluated the impact of leadership style on organizational culture in news agencies under the Ministry of Culture and Islamic Guidance.

The results showed that leadership style and its dimensions (organizational behavior, individual behavior, and internal intention) positively and significantly affect organizational culture. It means that the appropriate leadership style leads to the improvement of organizational culture among the staff of the news agencies under the Ministry of Culture and Islamic Guidance. In this regard, the results of this study are consistent with the results of Sarraf and Rokhchkar (2018), Jafari Harandi and Najafi (2017), Samadi Miarkalaei et al. (2015), and Aghajani et al. (2012 and they verify that there is a significant relationship between leadership style and organizational culture. Also, Ozcan and Ozturk (2020), Khan et al. (2020), Nguyen (2010), Castiglione (2016), Ramanido (2011), Qamasoglu and Ilsi (2009), Keskin (2009), and Lim and Kurati (2013) in their research found similar results, which confirms the findings of the present study.

It should also be noted that one of the topics that has received much attention in recent decades is organizational culture. The consistency between the managers' leadership style and their organizational culture has become very important. Although organizational culture is a set of shared beliefs and values that affect the thinking and behavior of members of an organization, it should always be noted that there are apparent differences between the basic aspirations, beliefs, and norms of senior management with low-level management or employees. The strength and effectiveness of organizational culture bring the values and beliefs of all organizational levels closer to each other. To do this requires an effective leadership style. 
Organizational leaders can play an active role in creating and directing the organizational culture. They can create, maintain, and transform the organization's culture. On the other hand, organizational culture can also influence the leadership style because culture reflects organizational readiness. In this regard, transformative leaders will be successful. Transformational leadership is part of a new leadership paradigm that transforms people. It relates to moral values and long-term goalsassessing the motivations affecting the followers, satisfying their needs, and treating them as human beings are among the responsibilities of transformational leadership.

Transformational leadership increases the satisfaction of subordinates, their confidence in leadership, and their emotional commitment. Leaders with transformative behaviors have a set of positive practices in the organization. Leaders in the organization should engage the members in planning a vision for the future, achieving goals, having optimistic thinking about the future, and increasing the employee motivation to work. However, many works have been conducted in Iran under different titles.

However, all these works have never led us to the desired goal of organizations and institutions since, in our organizations, the models of organizational culture and the leadership style in news management, and the way of communication with the audience are not considered. In this situation, the formation of an appropriate model of organizational culture, as well as the appropriate model of leadership style and organizing the relationship with the audience in order to link decisions, organizational goals, customer honors, and organizational excellence, is possible through achieving appropriate, efficient, and practical patterns, thereby the confusion will disappear, and the ability to achieve the desired results will increase. The audience is considered as the principal capital in the media organizations. Therefore, the focus of any organization should be on the audience, which requires them to look at expectations from their perspective. Paying attention to it leads to forming a local leadership style and organizational culture that helps organizations improve.

\section{References:}

Abzari, M., Teymouri, H., Delvi, M.R. 2008. Investigating the components of organizational culture using the cultural pathology approach. Culture Strategy Quarterly. Winter, 1(4), 119-137.

Aghajani, T., Azizi, G., Shoghi, B., Rezazadeh, A., Dehghan Najmabadi, A. 2012. Investigating the effect of leadership style on organizational culture (Case study: Pars Aluminum Company, Kaveh Industrial City). Cultural management Journal. Summer, 6(2), 66-80.

Ansari, M.I., Shaemi Bozorg, A., Safari, A. 2011. Providing a model of organizational culture management with a grounded theory (Case study: a manufacturing company). Journal of Applied Sociology, 22(42), 142-121.

Atikah, K., Qomariah, N. 2020. The Effect of Leadership Style and Organizational Culture and Work Motivation on Lecturer Performance. Jurnal Manajemen Dan Bisnis Indonesia, 6(2), 216-227. 
Castiglione, J. 2016. Facilitating employee creativity in the library environment: An important managerial concern for library administrators. Library management, 29, 52-53.

Danesh Fard, K., Shahabinia, S. 2011. Investigating the relationship between organizational culture and the establishment of knowledge management in the electricity company of the Executive Deputy of Northeast of Tehran. Management Quarterly, 17, 2-10.

Delavar, A. 2011. Research Methods in Psychology and Educational Sciences. 10th edition, Tehran: Virayesh press.

Dulewicz, V., Higgs, M. 2005. Assessing leadership styles and organizational context. Journal of Managerial Psychology, 20(2), 105-123.

Erniwati, S., Ramly, M. Alam, R. 2020. Leadership style, organizational culture, and job satisfaction at employee performance. Point of View Research Management, 1(3), 09-18.

Eyal, O., Kark, R. 2004. How do transformational leaders transform organizations? A study of the relationship between leadership and entrepreneurship. Leadership and Policy in Schools, 3(3), 211-235.

Fein, E.C., Tziner, A., Vasiliu, C. 2010. Age cohort effects, gender, and Romanian leadership preferences. Journal of Management Development, 29(4), 364-376.

Fisher, C.D. 1979. Transmission of positive and negative feedback to subordinates: A laboratory investigation. Journal of Applied Psychology, 64(5), 533.

Garvey, B., Williamson, B. 2002. Beyond knowledge management: Dialogue, creativity and the corporate curriculum. Pearson Education.

Gholami, A., Rajaipour, S., Karami Mohammadabadi, E., Maleki Moghaddam, M.S. 2013. Investigating the Relationship between Organizational Structure, Creativity and Organizational Learning of Employees in Lorestan University. 2nd National Conference on Modern Management Sciences, Gorgan. https://civilica.com/doc/231891.

Gholipour, A. 2001. Leadership style as the determining factor in the formal organizational structure. Journal of Management Knowledge, 14(53), 75-100.

Gumusluoglu, L., Ilsev, A. 2009. Transformational leadership, creativity, and organizational innovation. Journal of business research, 62(4), 461-473.

Hoseini, F., Rayej, H., Stiri, M., Sharifi, S.H. 2010. Investigating the relationship between organizational culture and transformational leadership styles and leader-follower exchange. Journal of Public Administration, spring and Summer, 2(4), 55-72.

Jafari Harandi, R., Najafi, H. 2017. The Impact of Leadership Style on Human Resource Performance Mediated by Organizational Silence. Journal of Improvement and Transformation Management Studies, 26(85), 85-57.

Keskin, H. 2006. Market orientation, learning orientation, and innovation capabilities in SMEs: An extended model. European Journal of Innovation Management.

Khan, M.A., Ismail, F.B., Hussain, A., Alghazali, B. 2020. The interplay of leadership styles, innovative work behavior, organizational culture, and organizational citizenship behavior. SAGE Open, 10(1), 2158244019898264.

Lim, J.Y., Croartie, F. 2013. Transformational Leadership, Organizational Culture and Organizational Effectiveness in Sport Organizations. The Sport Journal, 4(4), 111-169.

Nguyen, H.N. 2010. The impact of leadership behaviors and organizational culture on knowledge management practices in small and medium enterprises. Griffith University. 
Ozcan, O., Ozturk, I. 2020. Impact of organizational culture and leadership styles on employee performance: A research study on the banking industry. Research Journal of Business and Management, 7(1), 45-55.

Pinder, C.C., Harlos, M.S. 2015. Voice and Silence in Organizations. Bingley, UK: Emerald Press.

Purba, T., Lasise, S., Maming, J. 2021. The Influence of Leadership Style and Organizational Culture on Employee Performance through Organizational Commitment as Intervening Variable. Hasanuddin Journal of Applied Business and Entrepreneurship, 4(2), 93-105.

Ramanaidu, S.K. 2011. Uncovering The Relationship between Transformational Leadership, Organizational Culture, Affective Commitment and Employee Performance: The Case of a Malaysian Educational Institution. Doctoral Dissertation, University of Newcastle. Faculty of Business and Law, Newcastle Business School.

Reidhead, C. 2020. Impact of organizational culture on employee satisfaction: A case of Hilton hotel, United Kingdom. Journal of Economics and Business, 3(1), 45-60.

Rozi, A., Agustin, F., Hindriari, R., Rostikawati, D., Akbar, I.R. 2020. The Effect of Leadership on Employee Performance at PT. Stella Satindo in Jakarta. HUMANIS (Humanities, Management and Science Proceedings), 1(1), 134-146.

Samadi Miarkalaie, H., Samadi Miarkalaie, H., Aghajani, H. 2016. Explaining the role of transformational leadership style in organizational culture. Journal of Organizational Culture Management. Summer, 14(2), 519-499.

Santoso, P.B., Zuniawan, A., Wijayanti, L.M., Hadi, A.H. 2020. The Impacts of Innovative Work Behavior, Leadership Style, and Organizational Culture on Food Industries Performance. Journal of Educational Management and Human Resources Development, 1(1), 1-9.

Saraf, F., Rokhekar, H. 2018. Explaining the Relationship between Transformational Leadership Styles. Organizational Culture and Performance. Accounting Perspective and Management Quarterly, 1(3), 68-55.

Setiawan, R. 2020. A Literature Review: The Relationship and Measurement of Servant Leadership, Organizational Commitment, Organizational Culture to Employee Satisfaction, Employee Engagement, and Employee Performance. Doctoral dissertation, Petra Christian University.

Tusi, M.A. 2013. Organizational Culture. Tehran: Public Management Training Center press. Wanasida, A.S., Bernarto, I., Sudibjo, N., Pramono, R. 2021. Millennial transformational leadership on organizational performance in Indonesia fishery startup. The Journal of Asian Finance, Economics, and Business, 8(2), 555-562. 